\title{
Prevalence of SARS-CoV-2 RNA on inanimate surfaces: a systematic review and meta-analysis
}

\author{
Simone Belluco ${ }^{1}$ (D $\cdot$ Marzia Mancin ${ }^{1} \cdot$ Filippo Marzoli $^{1} \cdot$ Alessio Bortolami $^{2} \cdot$ Eva Mazzetto $^{2} \cdot$ Alessandra Pezzuto $^{1}$. \\ Michela Favretti $^{1}$ - Calogero Terregino ${ }^{2} \cdot$ Francesco Bonfante $^{2} \cdot$ Roberto Piro $^{1}$
}

Received: 25 February 2021 / Accepted: 29 June 2021 / Published online: 27 July 2021

(c) Springer Nature B.V. 2021

\begin{abstract}
Coronavirus disease (COVID-19) is a respiratory disease affecting many people and able to be transmitted through direct and perhaps indirect contact. Direct contact transmission, mediated by aerosols or droplets, is widely demonstrated, whereas indirect transmission is only supported by collateral evidence such as virus persistence on inanimate surfaces and data from other similar viruses. The present systematic review aims to estimate SARS-CoV-2 prevalence on inanimate surfaces, identifying risk levels according to surface characteristics. Data were obtained from studies in published papers collected from two databases (PubMed and Embase) with the last search on 1 September 2020. Included studies had to be papers in English, had to deal with coronavirus and had to consider inanimate surfaces in real settings. Studies were coded according to our assessment of the risk that the investigated surfaces could be contaminated by SARS-CoV-2. A meta-analysis and a metaregression were carried out to quantify virus RNA prevalence and to identify important factors driving differences among studies. Thirty-nine out of forty retrieved paper reported studies carried out in healthcare settings on the prevalence of virus RNA, five studies carry out also analyses through cell culture and six tested the viability of isolated viruses. Overall prevalences of SARS-CoV-2 RNA on high-, medium- and low-risk surfaces were $0.22\left(\mathrm{CI}_{95}[0.152-0.296]\right), 0.04\left(\mathrm{CI}_{95}\right.$ [0.007-0.090]), and $0.00\left(\mathrm{CI}_{95}[0.00-0.019]\right)$, respectively. The duration surfaces were exposed to virus sources (patients) was the main factor explaining differences in prevalence.
\end{abstract}

Keywords Coronavirus $\cdot$ COVID-19 $\cdot$ Event rate $\cdot$ Epidemiology $\cdot$ Fomites $\cdot$ Risk $\cdot$ SARS-CoV-2

\section{Introduction}

Coronavirus disease 19 (COVID-19) is caused by the Severe Acute Respiratory Syndrome coronavirus type 2 (SARSCoV-2). To date, the SARS-CoV-2 ongoing pandemic has caused more than 85 million cases in 191 countries, reaching around 2 million deaths worldwide by January 2021 [1].

COVID-19 case fatality rate was estimated to be $0.25 \%$ to $10 \%$ [2] with important differences among countries due to disparities in the number of people tested, demographics, characteristics of the healthcare system and other factors [3]. Symptoms caused by COVID-19 are variable and can

Simone Belluco

sbelluco@izsvenezie.it

1 Department of Food Safety, Istituto Zooprofilattico Sperimentale Delle Venezie, Legnaro, Italy

2 Division of Comparative Biomedical Sciences, Istituto Zooprofilattico Sperimentale Delle Venezie, Legnaro, Italy include fever, cough, loss of sense of smell, and breathing difficulty. Most people are asymptomatic or mildly symptomatic, but some individuals can develop an acute respiratory distress syndrome, requiring medical support in intensive care units [4].

The main transmission route for SARS-CoV-2 to a susceptible individual appears to be direct contact with an infected subject who releases the virus into the air by sneezing, coughing, or speaking [5]. It has been hypothesized that SARS-CoV-2 could be also transmitted by indirect contact through fomites, defined as contaminated porous and nonporous surfaces or objects [6, 7]. For example, in many bacterial infectious diseases, the role of fomites is recognized as determinant in their transmission, especially in the nosocomial environment $[7,8]$. Although this transmission route is well-known for some respiratory and enteric pathogens, its role in SARS-CoV-2 transmission is still largely unknown [9]. 
To establish SARS-CoV-2 ability to be transmitted through fomites, we need multiple examples of indirect evidence; otherwise, evaluation of this transmission route is hardly demonstrable. Moreover, we have to consider viral persistence in the environment, which not only depends on structural characteristics of the virus, for example, the presence of the envelope [10], but also on many environmental factors such as temperature, moisture, exposure to UV and surface characteristics [7]. The persistence of human and veterinary coronaviruses on different surfaces was recently reviewed by Marzoli et al. [11].

Since the beginning of the pandemic, besides the wearing of face masks, several public guidelines recommended cleaning and disinfection, use of gloves and hand hygiene as preventive measures, reverting to the precautionary principle due to the scarcity of available evidence [12]. Indeed, understanding the role of fomites in SARS-CoV-2 transmission is imperative, not only to define the appropriate measures of prevention, but also to improve their management under an ecological perspective. High levels of fomite transmission could make social distancing and wearing face masks insufficient actions to prevent the virus spreading among people. Alternatively, if fomite transmission were a negligible route of infection for this virus, we could try to limit the prodigious and widespread use of chemical disinfectant products or to reduce the amount of waste caused by unnecessary personal protective equipment (PPE), which is negatively affecting our environment [13].

In the present work, we collected, evaluated and discussed all existing data on the role of inanimate surfaces in the indirect transmission of SARS-CoV-2.

\section{Materials and methods}

We applied systematic review methodology using a specific, non-extensive approach in order to rapidly retrieve and screen relevant records from multiple databases.

Details of the systematic reviews carried out were the following:

Review question What is the prevalence of coronaviruses on surfaces in real settings?

Population surfaces (objects and environment).
Outcome prevalence of coronavirus RNA and/or infective viruses (Effect size: event rate).

We considered all papers published in peer-reviewed journals in English language. No time limits were imposed. We searched PUBMED and EMBASE (Title/Abstract and Title, Abstract, Author keywords, respectively) with the search terms reported in Table 1. The last date searched was 01/09/2020. To supplement the search process, we also used the final list of papers selected to carry out a backward reference search in order to identify potential missing evidence.

We applied several criteria to select eligible papers: (1) had to be written in English (2) had to report data belonging to primary research; (3) had to deal with coronavirus; (4) had to consider inanimate surfaces in real settings (not experimental contamination).

We carried out the screening process using EPPI-4 Reviewer software [14].

In the case of a poorly explicative abstract or in the case of doubt about the available data, the paper was included and evaluated at the full-text level. Thereafter, four reviewers (SB, FM, MF, AP) screened all papers (in duplicate) obtained via the initial literature search according to Title/ Abstract and full text, independently (parallel method). Disagreements were resolved through consensus. For each relevant paper, one reviewer collected data and a second reviewer checked the collected data against the original paper (sequential method). We coded all papers according to the previously chosen parameters, and we recorded all data.

We collected data in pre-defined forms for a number of variables belonging to three categories (characteristics, design, and methodology) useful to describe the studies and to report results, together with relevant variables.

The methodology of included studies can have an influence on the results. To describe such possibilities, we collected information on the following parameters: analytical method/s, viability assessment, compliance statement to WHO guidelines concerning sampling [15] and/or detection [16], control of air contamination with droplets containing virus, PCR target genes, and size of the sampling area. According to WHO guidelines for sampling [15], a blank control swab should be included to assess the risk of aerosol/ air contamination at the time of sampling. For this reason, air sampling was included as a relevant criterion.

Table 1 keywords use to retrieve relevant records

Keywords (Title/Abstract)

Coronavirus OR coronaviruses

OR CoV OR sars OR mers

OR sars-cov OR mers-cov

OR sars-cov-2
AND Surface OR surfaces OR environment OR environmental OR packaging OR packages OR package OR food OR skin OR hand

OR hands OR fomite
AND Presence OR detection OR detect OR isolated $\mathrm{OR}$ isolation 


\section{Synthesis of results}

We used event rate (prevalence) as effect size. We collected relevant data from primary studies, but we excluded data referring to surfaces that had been cleaned and/or disinfected immediately before sampling, and surfaces of clinical tools that were used inside COVID-19 patients (i.e. endotracheal tube). From each study on SARS-CoV-2, we extrapolated three parameters: the virus source (spreading subject or fomites), the location of surface where the sampling was performed and the duration of exposure. Briefly, the virus source, defined as the origin of viral contamination, distinguished among: direct contamination from a confirmed positive patient; direct contamination from a suspected positive patient; indirect contamination (this means without direct contact with a positive patient) and; an unknown viral source. The location of surface permitted us to evaluate the sampling site for each study and to group sampled objects and surfaces: in strict contact with the patient; in close proximity to the patient; in the healthcare environment and; in areas not related to the healthcare environment. Finally, we assigned, according to the available information, to each investigated surface, the possible duration of exposure to a viral source. Those parameters are described in detail in Table 2 and were subsequently scored from 1 to 4, as reported in Fig. 1.

For each study, we evaluated the parameters and assigned each one a relative score. The addition of those scores allowing us to synthesize the likelihood of the presence of SARSCoV-2 RNA on a given surface as high, medium, low or very low. In metaregression, this scoring system was also used to investigate the influence of each parameter (used as moderator) on the risk of viral contamination.

We defined as a "study" an investigation performed on a group of surfaces which shared the same possibility of contamination. We defined as a "cluster" a group of studies belonging to the same paper. Papers reporting studies on coronavirus other than SARS-CoV-2 were not included in our categorization or in the meta-analyses; however, their results are discussed in the text.

\section{Pooled prevalence}

A cumulative variable "contamination risk" was defined according to Fig. 1. Meta-analyses and meta regressions were performed using the metafor package [17] of the statistical software R (version 3.6.0) [18]. Meta-analysis is a statistical method that combines outcomes of primary studies with a weight assigned according to the inverse of the variance. For this reason, the variance is a critical parameter, which has to be calculated when studies reporting zero prevalences are included. The Freeman-Tukey (double arcsine) transformation for proportion [19] was used to obtain a variance stabilizing transformation without applying continuity corrections or removing studies from the meta-analysis, and to appropriately weight studies with zero prevalence and high number of samples [17, 20]. We combined transformed prevalence estimates in meta-analysis using a multilevel random-effect model and later back-transformed in the original metrics [21]. We applied a multilevel structure to take into account the multiple estimated prevalences included in the same paper (cluster) referring to different studies (rma.mv function from metafor package; [17]).

We carried out several metaregression analyses to account for the applied study categorization and single factor scoring:

- a metaregression with "contamination risk" as moderator;

- a metaregression with virus source as moderator;

- a metaregression with location of surface as moderator;

- a metaregression with duration of exposure as moderator;

- a multivariate metaregression analysis including each of three risk factors (virus source, location of surface and duration of exposure) and their interactions as different moderators. The amount of heterogeneity was estimated using the $\mathrm{Q}, \mathrm{T}^{2}$ and $\mathrm{I}^{2}[22,23]$ statistics obtained by Restricted Maximum Likelihood (REML), which is considered approximately unbiased and relatively efficient [24]. In the multilevel model, the $\mathrm{T}^{2}$ value for the total heterogeneity can be divided into two variance components, one for the between-cluster (papers) heterogeneity $\left(\sigma^{2}\right)$ and one for the within-cluster (studies within paper) heterogeneity $\left(\sigma_{2}^{2}\right)$.

Heterogeneity was explored through univariate and multivariate metaregression using the multilevel models [25, 26]. Moderator significance was assessed through the Likelihood Ratio Test (LRT) by comparing the proportional reduction for heterogeneity ( $\mathrm{T}^{2}$ value) of the full and reduced models.

The percentage of reduction in the total variance due to the moderator was evaluated using pseudo $\mathrm{R}^{2}$ statistics. Maximum Likelihood (ML) estimate instead of REML was used to compare two nested models and to evaluate the importance of the moderators [17]. We made several attempts to explain heterogeneity through moderators describing the levels of exposure of different surfaces to viral contamination. In cases of moderator significance, determined according to the Likelihood Ratio Test, Tukey's all-pairwise comparisons were performed using the False Discovery Rate correction [27] by glht function from multicomp package [28]. 
Table 2 Details of the scoring system applied to categorize studies

\begin{tabular}{|c|c|c|}
\hline & Category & Description \\
\hline \multirow[t]{4}{*}{ Virus source } & Patients confirmed positive & Direct contact with RT-PCR confirmed SARS-CoV-2 positive individual/s \\
\hline & Patients suspected positive & $\begin{array}{l}\text { Direct contact with suspected (diagnosis based on any method or criteria } \\
\text { other than molecular testing) SARS-CoV-2 positive individual/s }\end{array}$ \\
\hline & Indirect contact fomites & $\begin{array}{l}\text { Contact with potentially contaminated objects from confirmed SARS- } \\
\text { CoV-2 positive individual/s }\end{array}$ \\
\hline & Unknown or SARS-CoV-2 negative & $\begin{array}{l}\text { Direct contact with individual/s with unknown or confirmed negative } \\
\text { status for SARS-CoV-2 }\end{array}$ \\
\hline \multirow[t]{4}{*}{ Location of surface } & Objects in strict contact with patient/s & $\begin{array}{l}\text { Bed objects (e.g. bed rail, bed table, bedsheets), patient mobile phone, } \\
\text { pillows, duvet cover, call bell... }\end{array}$ \\
\hline & Objects and surfaces in proximity to patient/s & $\begin{array}{l}\text { PPE and clinical equipment, clinical monitoring devices, nurse rolling } \\
\text { carts, ward computer or telephone, toilet door handle, toilet bowls and } \\
\text { drains... }\end{array}$ \\
\hline & Healthcare related areas & $\begin{array}{l}\text { Accommodation and waiting rooms, buffer rooms, elevators, nurse/staff } \\
\text { work-stations, office area, public toilets, rest room... }\end{array}$ \\
\hline & Non healthcare related areas & $\begin{array}{l}\text { Outdoor or public environment areas and surfaces (e.g. parking lot, } \\
\text { classroom) }\end{array}$ \\
\hline \multirow[t]{4}{*}{ Duration of exposure } & More than $12 \mathrm{~h}$ & $\begin{array}{l}\text { Areas and surfaces sampled after potential prolonged exposure to viral } \\
\text { contamination and without effective disinfection procedures reported } \\
\text { (e.g. bed linings, patient's personal objects) }\end{array}$ \\
\hline & Up to $12 \mathrm{~h}$ & $\begin{array}{l}\text { Areas and surfaces sampled after being potentially exposed for an inter- } \\
\text { mediate period of time to a viral source or subjected to regular disinfec- } \\
\text { tion procedures (e.g. face masks, regularly disinfected floors) }\end{array}$ \\
\hline & Up to $1 \mathrm{~h}$ & $\begin{array}{l}\text { Areas and surfaces sampled after short exposure to a viral source (e.g. } \\
\text { surfaces in a laboratory processing SARS-CoV-2 diagnostic samples, } \\
\text { samples taken to assess efficacy of disinfection protocols) }\end{array}$ \\
\hline & Unknown/less than $20 \mathrm{~min}$ & $\begin{array}{l}\text { Areas and surfaces sampled after very short exposure to potential viral } \\
\text { source or where the duration of potential exposure could not be inferred } \\
\text { (e.g. corridor) }\end{array}$ \\
\hline
\end{tabular}

To account for the risk of bias within studies, we evaluated the influence of sampling procedure and analytical methods on prevalence, and we ran two additional metaregressions with two moderators potentially linked with quality, according to data availability. The chosen factors were: the presence of a blank control or an alternative method to ascertain the absence of SARS-CoV-2 in air and; the use of two or more RNA targets for PCR. In the case of a significant moderator, we tested the interaction with the moderator "contamination risk".

We took into consideration the risk of bias across studies with a mixed strategy. We applied a number of a priori exclusion criteria (eligibility criteria), and in addition, studies had to deal with SARS-CoV-2 (criterion for inclusion in meta-analysis). Additional factors potentially accounting for differences among studies were considered through the scoring system. The choice of surfaces that were sampled is the main difference in study design able to affect the results of each investigation, and thus, this could be an important source of bias. The risk of a surface becoming contaminated with virus genetic material depends on several factors. We considered as particularly relevant: the presence and the characteristics of the virus source; the proximity of the sampled surface to the viral source, and; the duration of exposure of the surface to the virus source. All these factors were considered when we scored and categorized the studies, as explained above, and were included in the metaregression to explain heterogeneity. Details about the criteria we used to assign different scores within moderators are reported in Table 2. Researchers (FB, AB, and EM) with expertise in virology and direct knowledge of SARS-CoV-2 experimental behavior assessed the risk of bias issue. In particular, we addressed this issue by categorizing the studies according to the scheme described above. Note that although we chose factors that we considered useful, this is inevitably a subjective procedure and alternative categorizations could be equally valid.

In addition, to account for bias, we ran sensitivity analyses in each model in order to evaluate the presence of outliers or leverage studies and their potential influence on each model. Four parameters were examined: the externally studentized residuals; the DFBETAS values; the Cook's distance; and 
the hat function. Influence was defined according to metafor package criteria (DFBETAS value is larger than 1, the lower tail area of a chi-square distribution with $p$ degrees of freedom cut-off by the Cook's distance is larger than 50\% OR hat value $>3(\mathrm{p} / \mathrm{k}))$. Furthermore, studies were excluded one by one from the model to evaluate relevant changes in heterogeneity ( $\mathrm{T}^{2}$ and $\left.\mathrm{Q}\right)$ and pooled estimates. Finally, publication bias was evaluated through Egger's regression test, obtained by including the standard error or the variance of the effect sizes as a moderator in the model [29]. The significance of the moderator suggests the presence of publication bias. A p-value $<0.05(p)$ was considered as significant in the statistical analysis.

Table 3 characteristics of included papers dealing with coronavirus presence on surfaces

\begin{tabular}{|c|c|}
\hline $\mathrm{HcoV}$ & 4 \\
\hline Public areas & 4 \\
\hline Finland & 1 \\
\hline Saudi arabia & 2 \\
\hline USA & 1 \\
\hline MERS-CoV & 2 \\
\hline Healthcare facilities & 2 \\
\hline South Korea & 2 \\
\hline SARS-CoV & 2 \\
\hline Health care facilities & 2 \\
\hline Canada & 1 \\
\hline Thailand and Taiwan & 1 \\
\hline SARS-CoV-2 & 32 \\
\hline Health care facilities & 29 \\
\hline Canada & 1 \\
\hline China & 12 \\
\hline France & 1 \\
\hline Ireland & 1 \\
\hline Italy & 4 \\
\hline Singapore & 3 \\
\hline South Korea & 3 \\
\hline Spain & 1 \\
\hline Turkey & 1 \\
\hline UK & 1 \\
\hline USA & 1 \\
\hline Health care facilities and mass facilities & 1 \\
\hline South Korea & 1 \\
\hline Health care facilities, mass facilities and public areas & 1 \\
\hline Greece & 1 \\
\hline Public areas & 1 \\
\hline Japan & 1 \\
\hline Total & 40 \\
\hline
\end{tabular}

\section{Results}

\section{Study selection}

After literature searches in the selected databases, we retrieved 2105 records, 1142 remained after duplicate removal and finally, after title/abstract and full text screening, 40 papers were selected for inclusion (Fig. 2).

\section{Study characteristics}

After the screening process, we included 40 papers reporting data about coronaviruses' presence on surfaces. Thirty-two papers (all published in 2020) investigated the presence of SARS-CoV-2 RNA and reported data for 88 studies, whereas eight papers (all published before 2020) investigated other coronaviruses. Out of 40 papers, 23 were full articles, while the others were short communications, letters, dispatches or other types of publications. Twenty-two papers described studies carried out in Southeast Asia. Twenty-nine out of 32 studies were fully carried out in healthcare facilities where a known source of contamination (infected patients) was present. Emergency departments, isolation rooms and intensive care units were the most frequently investigated areas. Six studies considered high contact surfaces in the public environment, although four of them dealt with common human coronaviruses (HCoVs) (Table 3). A wide number of different surfaces was investigated, but the surface material was not reported (with only one exception), and thus, it was impossible for us to investigate the role of surface materials on virus presence. Full details on the 40 papers' characteristics are reported in "Appendix" Table 6.

\section{Risk of bias within studies (quality evaluation)}

The parameters influencing the papers' characteristics are summarized in Table 4 . We observed high variability regarding the sampling procedure; in particular, the swabbed area ranged from $9 \mathrm{~cm}^{2}$ to $100 \mathrm{~cm}^{2}$, with most studies not reporting this information. Some studies referred to the WHO guidelines (published in February 2020). WHO guidelines recommend swabbing a 25 $\mathrm{cm}^{2}$ surface area, and to put the swab in 1-3 $\mathrm{ml}$ of Viral Transport Medium. Multiple sampling for each surface is suggested, as is the inclusion of a blank control swab (to determine whether aerosol/air contamination at the time of sampling could interfere with study results) [15]. In our current analysis, the surfaces selected for sampling purposes by the different studies were highly varied, but most of them were listed as suggested surfaces in WHO guidelines [15]. It should be emphasized that most studies, 


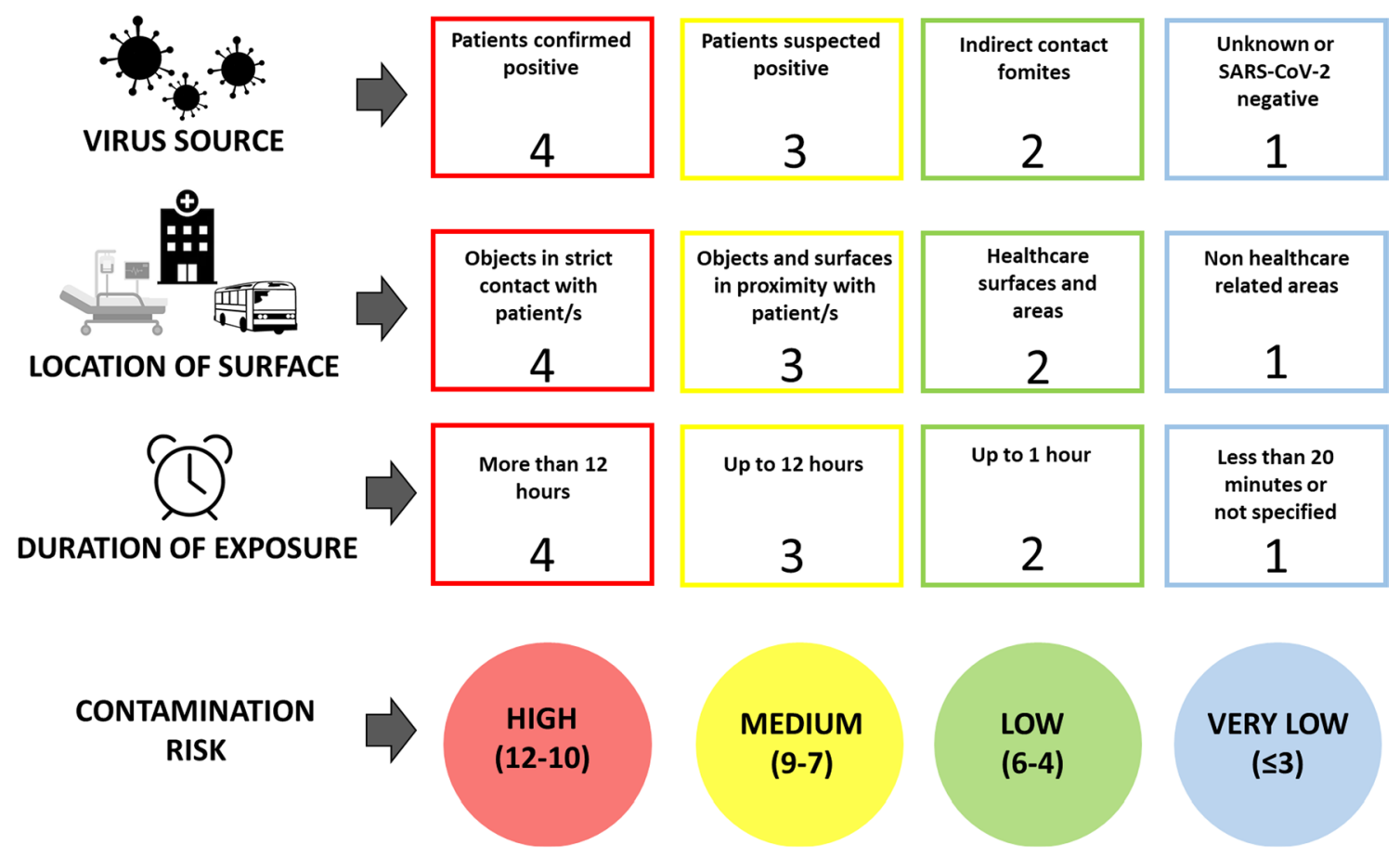

Fig. 1 scheme describing the categorization system applied to the included studies

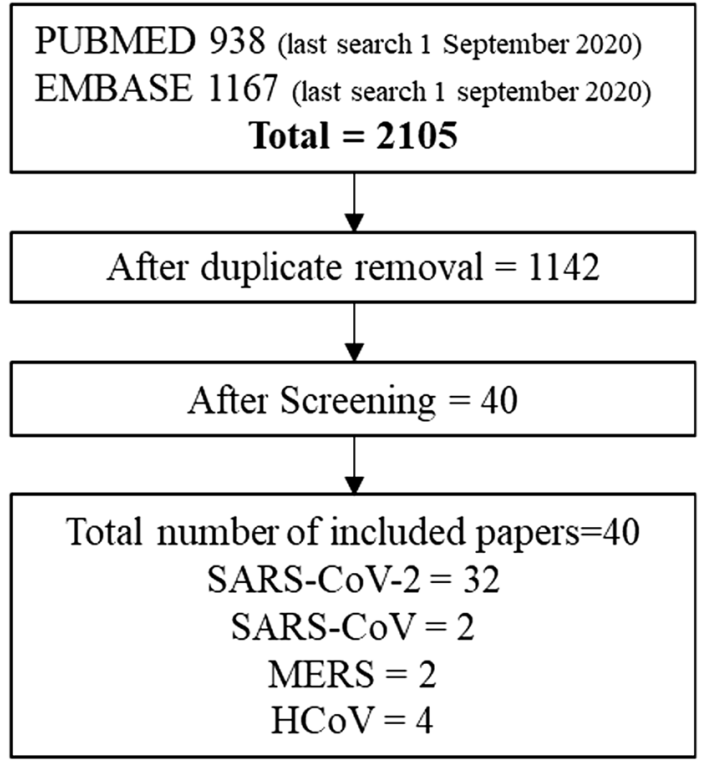

Fig. 2 results of the paper selection process

according to the WHO suggestion, investigated mainly high contact surfaces, with a higher risk of contamination, and not randomly chosen surfaces. All studies except one carried out PCR analysis on swabs. Five studies (four targeting SARS-CoV-2) also carried out virus viability assays in cell culture for PCR positive samples.
As regards the risk of bias assessment, the moderators tested were not significant. In particular, both, the presence of a blank control or an alternative method to ascertain the absence of SARS-CoV-2 in air and the use of two or more RNA target for PCR were non significant with p-values of, respectively, 0.1665 and 0.2636 .

\section{Results of individual studies}

We observed high variability in the prevalence of RNA contamination on surfaces as reported by individual studies. Study characteristics could, in part, explain such differences and were taken into account in our synthesis of results. The results of individual studies dealing with SARS-CoV-2 are summarized in Fig. 3.

With regards to the eight papers dealing with coronaviruses other than SARS-CoV-2, four studies investigated the presence of $\mathrm{H}-\mathrm{CoV}$. Out of these, two studies evaluated the frequency of $\mathrm{H}-\mathrm{CoV}$ contamination on airport surfaces and reported prevalences of 3.3\% [70] and 7.5\% [51]. One study investigating the frequency of contamination by respiratory pathogens of areas and surfaces in places associated with worship reported an overall $\mathrm{HCoV}$ prevalence of $1.4 \%$ [42], whereas in a university classroom, desktops and the doorknob were the surfaces most commonly contaminated with $\mathrm{H}-\mathrm{CoV}$ [34]. The prevalence of SARS-CoV contamination 


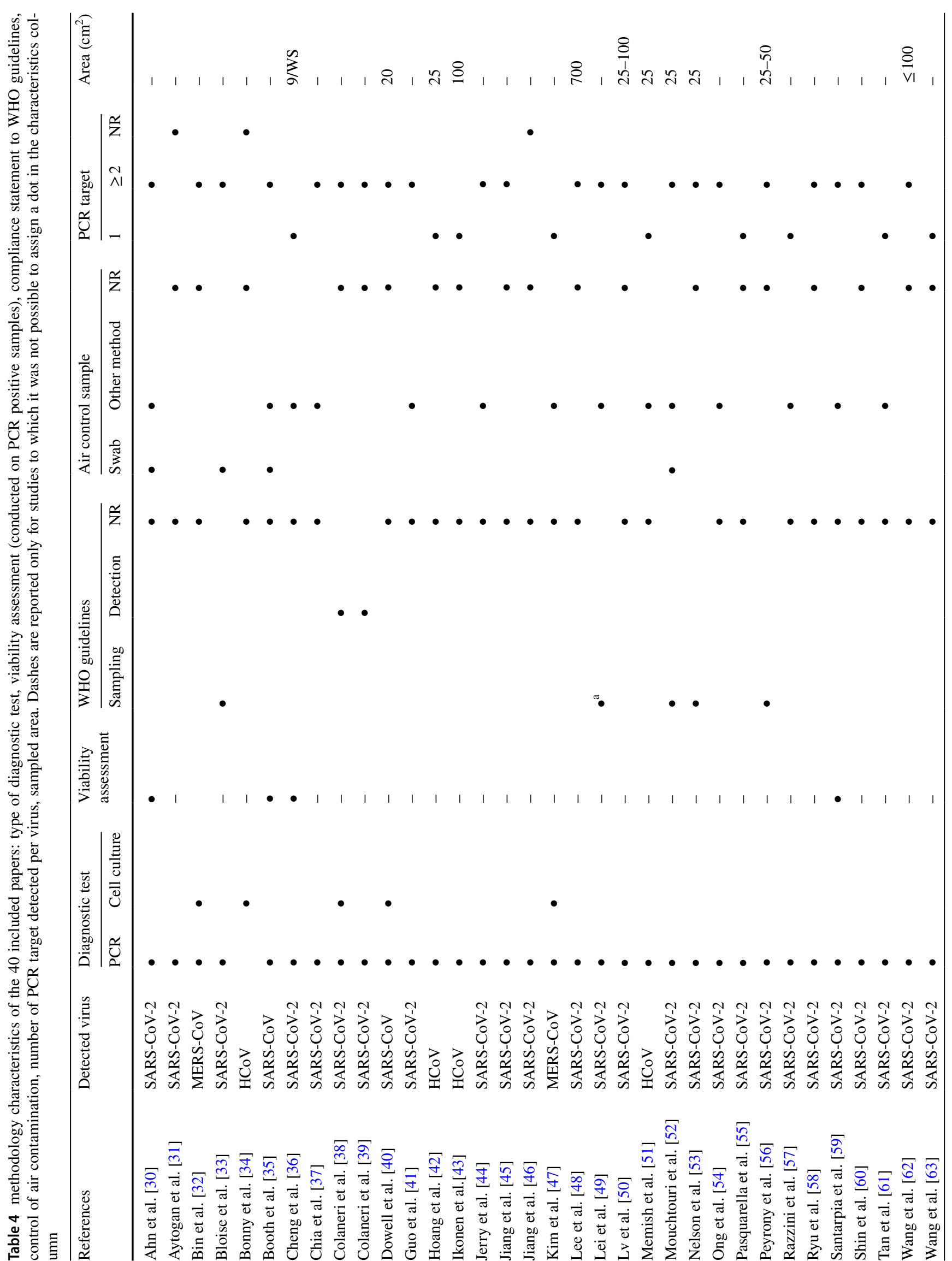




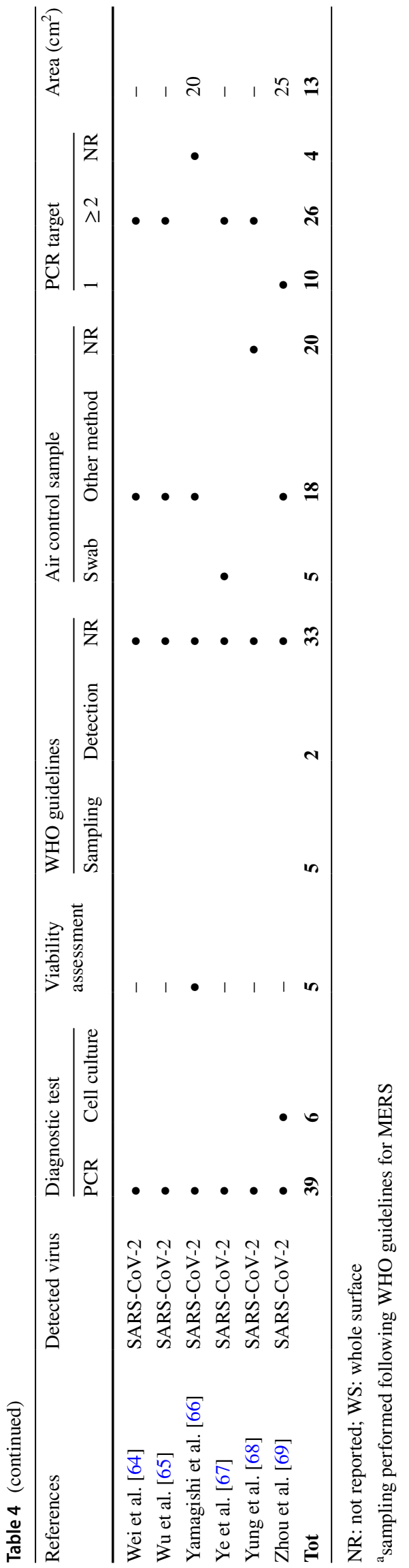

was investigated in two studies on hospital surfaces, and both revealed the high frequency of SARS-CoV contamination on surfaces exposed to SARS-CoV positive patients $[35,71]$. The frequency of MERS-CoV contamination was investigated on hospital surfaces, and the frequency of contamination on the sampled surfaces was over $20 \%$ in both the retrieved studies [32, 47].

Only 11 studies reported data about the viability of coronaviruses. In particular, six studies were conducted on SARS-CoV-2 [30, 36, 38, 59, 66, 69], two on SARS-CoV $[35,40]$, two on MERS-CoV [32, 47], and one on H-CoV [34]. Among them, five studies conducted the viability assessment only on RT-PCR positive samples, while six studies performed cell culture analysis on all the sampled surfaces (Table 4). Only three studies detected viable SARSCoV-2 on tested surfaces [30, 36, 59]; prevalences were $8.2 \%$ [30] and 5\% [36] of total sampled surfaces. Viability was also reported for MERS-CoV on 4.3\% [32] and 22.1\% [47] of total sampled surfaces, and for $\mathrm{HCoV}$ on $37.5 \%$ of total sampled surfaces [34].

\section{Synthesis of results}

We included 88 studies dealing with SARS-CoV-2 in the metaregression. Across all studies overall, SARS-CoV-2 RNA was detected on surfaces with a prevalence of 0.085 $\left(\mathrm{CI}_{95}[0.042-0.138]\right)$. When we assigned surfaces into different risk categories (high, medium and low), SARSCoV-2 RNA was detected with a prevalence of $0.22\left(\mathrm{CI}_{95}\right.$ [0.152-0.296]), $0.04\left(\mathrm{CI}_{95}[0.007-0.090]\right)$ and $0.00\left(\mathrm{CI}_{95}\right.$ [0.00-0.019]), respectively.

The moderator "contamination risk" was significant $(p<0.0001)$, and the proportional reduction in the total variance was $R^{2}=43 \%$. Multiple pairwise comparison of means (Tukey contrasts) resulted in a statistically significant difference of studies investigating high-risk surfaces vs studies investigating medium-risk surfaces $(p=2.56 \mathrm{e}-06)$ and of studies investigating high-risk surfaces vs studies investigating low-risk ( $p=2.91 \mathrm{e}-10)$ surfaces. Also the comparison between medium- and low-risk surfaces was significant $(p=0.011)$ (Fig. 3).

To account for the importance of different factors used to assign the category "contamination risk", the scores of each factor (virus source, location of surface and duration of exposure) were also taken into account separately.

The three moderators, taken individually, were all statistically significant as reported in Table 5. Heterogeneity was always significant according to $\mathrm{Q}$ statistics and around $90 \%$ when estimated as $\mathrm{I}^{2}$. The multiple comparison of means was run in each model between all paired variables. In the model considering virus source, only the comparison 


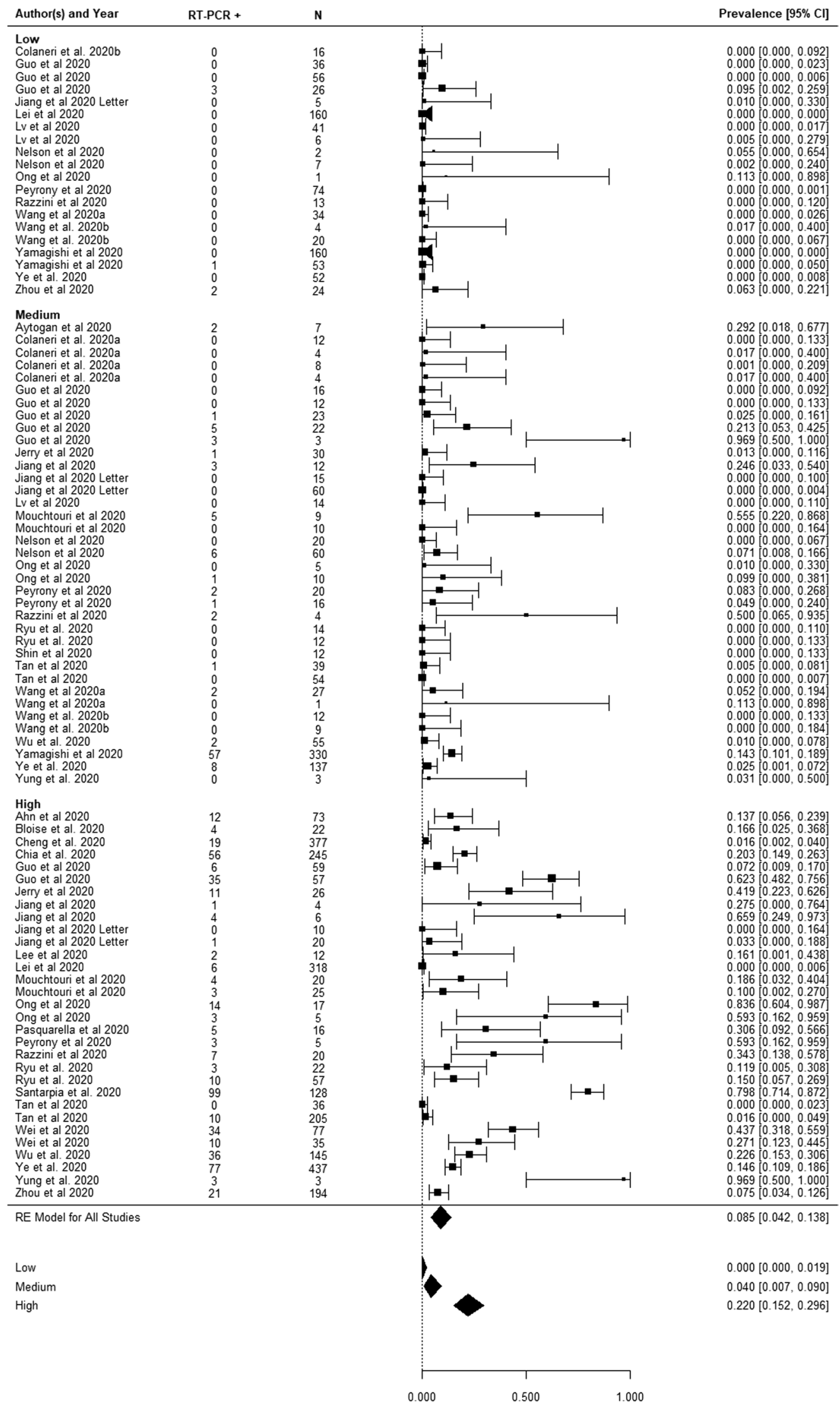

Fig. 3 forest plot with individual study results and result of metaregression with "contamination risk" as moderator 
between "direct contact-patients confirmed positive" and "indirect contact-fomites" showed a significant difference $(p=0.035)$. In the model with location of surface as the moderator, four pairwise comparisons resulted in significant differences: "objects and surfaces in proximity with patient/s" vs "healthcare surfaces and areas" $(p=2.67 \mathrm{e}-04)$, "objects in strict contact with patient/s" vs "healthcare surfaces and areas" ( $p=4.07 \mathrm{e}-04)$, "objects and surfaces in proximity with patient/s" vs "non-healthcare related areas" $(p=0.046)$ and "objects in strict contact with patient/s vs "non-healthcare related areas" ( $p=0.027)$.

In the case of duration of exposure, the significant pairwise comparisons were: "less than 20 min or unspecified" vs " 1 to $12 \mathrm{~h}$ " $(p=5.36 \mathrm{e}-05)$, "up to $1 \mathrm{~h}$ post disinfection" vs "1 to $12 \mathrm{~h}$ " ( $p=2.90 \mathrm{e}-05)$, "more than $12 \mathrm{~h}$ " vs "less than 20 min or unspecified" ( $p=1.26 \mathrm{e}-04)$ and "up to $1 \mathrm{~h}$ post disinfection" vs "more than $12 \mathrm{~h}$ " $(p=9.65 \mathrm{e}-04)$.

Even when all moderators were included in the multivariate model, heterogeneity was high, with $\mathrm{T}^{2} 0.036$ and $\mathrm{I}^{2}=87 \%$. According to this model, about $53 \%$ of the total variance was due to between-cluster differences, with the remaining $34 \%$ due to within-cluster differences. The remaining $13 \%$ was due to sampling variance. The proportional reduction in the total variance was $R^{2}=44 \%$. The estimated prevalence rates for each score are shown in Fig. 4.
In the multiple comparison test, only differences due to the moderator "duration of exposure" were significant: "less than 20 min or unspecified" vs " 1 to $12 \mathrm{~h}$ " $(p=0.003)$, "up to $1 \mathrm{~h}$ post disinfection" vs " 1 to $12 \mathrm{~h}$ " ( $p=4.4 \mathrm{e}-05)$, "more than $12 \mathrm{~h}$ " vs "less than 20 min or unspecified" ( $p=8.13 \mathrm{e}$ $04)$ and "up to $1 \mathrm{~h}$ post disinfection" vs "more than $12 \mathrm{~h}$ " $(p=8.82 \mathrm{e}-04)$.

In this last model, interactions among moderators were also evaluated, but they were not significant.

Sensitivity analysis was carried out in each model according to the definition of influence previously described. In the model without moderators, two studies $[54,59]$ were influential. In the model with "contamination risk" as the moderator, one study was influential [59]. We ran the model excluding the studies that proved to be influential, and in both cases, we obtained an overall prevalence of $0.073\left(\mathrm{CI}_{95}\right.$ [0.036-0.118]). In the model with moderators of "low" and "medium" contamination risk, small changes $(0.000$ $\mathrm{CI}_{95}[0.000 ; 0.013]$ and $0.036 \mathrm{CI}_{95}[0.006 ; 0.080]$, respectively) in prevalence occurred, whereas in the "high" risk category, prevalence decreased to $0.194 \mathrm{CI}_{95}[0.133 ; 0.262]$. In the models with the other moderators, the analysis of influence was affected by the non-homogeneous number of studies in different groups with the same scores. Full results of the sensitivity analysis are reported in Supplementary materials (Figures 1 to 5 ).

Table 5 results of the three models including a single moderator each

\begin{tabular}{lr}
\hline Virus source $(p=0.021) \mathrm{Q} p<0.0001 \mathrm{~T}^{2}=0.053 \mathrm{I}^{2}=91 \% \operatorname{Mod} p=0.02 \mathrm{R}^{2}=14 \%$ \\
Patients confirmed positive & $0.130 \mathrm{CI}_{95}[0.072-0.197]$ \\
Patients suspected positive & $0.061 \mathrm{CI}_{95}[0.00-0.220]$ \\
Indirect contact-fomites & $0.023 \mathrm{CI}_{95}[0.00-0.089]$ \\
Unknown or SARS-CoV-2 negative & $0.000 \mathrm{CI}_{95}[0.00-0.118]$ \\
Location of surface $p=0.0002) \mathrm{Q} \mathrm{p}<0.0001 \mathrm{~T}^{2}=0.049 \mathrm{I}^{2}=90 \% \operatorname{Mod} p=0.0002 \mathrm{R}^{2}=20 \%$ & $0.177 \mathrm{CI}_{95}[0.084-0.289]$ \\
Objects in strict contact with patient/s & $0.132 \mathrm{CI}_{95}[0.069-0.206]$ \\
Objects and surfaces in proximity with patient/s & $0.005 \mathrm{CI}_{95}[0.00-0.049]$ \\
Healthcare related areas & $0.000 \mathrm{CI}_{95}[0.00-0.110]$ \\
Non healthcare related areas & \\
Duration of exposure $(p<0.0001) \mathrm{Q} p<0.0001 \mathrm{~T}^{2}=0.040 \mathrm{I}^{2}=89 \% \mathrm{Mod} p<0.0001 \mathrm{R}^{2}=36 \%$ & $0.428 \mathrm{CI}_{95}[0.158-0.721]$ \\
More than $12 \mathrm{~h}$ & $0.164 \mathrm{CI}_{95}[0.104-0.234]$ \\
Up to $12 \mathrm{~h}$ & $0.017 \mathrm{CI}_{95}[0.000-0.059]$ \\
Up to $1 \mathrm{~h}$ & $0.000 \mathrm{CI}_{95}[0.000-0.020]$ \\
Unknown/less than 20 min &
\end{tabular}


Fig. 4 forest plot showing prevalences resulting from the multivariate model including three moderators

\begin{tabular}{l|r} 
RE Model for All Studies \\
Moderators \\
\hline Virus source \\
Patients confirmed positive \\
Patients suspected positive \\
Indirect contact - fomites \\
Unknown or SARS-CoV-2 negative \\
Location of surface \\
Objects in strict contact with patient/s \\
Objects and surfaces in proximity to patient/s \\
Healthcare related areas \\
Non healthcare related areas \\
Duration of exposure \\
More than 12 hours \\
Up to 12 hours \\
Up to 1 hour \\
Unknown/less than 20 minutes
\end{tabular}

In the model without moderators, the null-hypothesis of no relationship between the primary study's effect size and standard error was not rejected by Egger's test $(p=0.106)$. This implies that there is no evidence for small-study effects in the meta-analysis [72]. In contrast, Egger's test identified significant asymmetry in the funnel plots of all models with moderators $(p<0.01$; Figures 6 to 9 in the Supplementary material).

\section{Discussion}

Since the beginning of the current pandemic, the unknown role of indirect transmission has resulted in restrictive preventive measures such as cleaning, disinfection, glove use and hand hygiene in addition to use of face masks [12]. Moreover, there is scarcity of data about the frequency of contamination of different surfaces that could drive any refinement of preventive measures.

\section{Summary of evidence}

SARS-CoV-2 RNA was detected on surfaces with an overall prevalence of $8.5 \%$. Most studies ("Appendix" Table 6) were carried out in healthcare settings, and often in emergency department units, isolation rooms or intensive care units, with exposure to a direct or indirect virus source. In addition, surfaces were often chosen according to the extent of contact with patients. Following these considerations, in these areas, the prevalences detected are relatively low, possibly because of the disinfection protocols applied in such settings, as supported by the importance of the moderator "duration of exposure".

The moderator "contamination risk" built up from the score deriving from the categorization system was significant, and was able to summarize different risk factors potentially explaining surface contamination. The prevalences of SARS-CoV-2 RNA on low-risk surfaces were between 0 and $1.9 \%$. If we consider non-health care areas, such as public 
areas or the outside environment, we suggest the risk of a surface being contaminated is very low.

Duration of exposure greatly influenced the prevalence rate, whereas virus source and location of surface were significant in the single moderator models, losing significance in the multivariate model accounting for all moderators.

The moderator "virus source" was aimed at demonstrating the influence of a virus source, namely an infected individual actively shedding the respiratory pathogen, on surface contamination. The absence of such significance could be due to several factors: the presence of unrecognized or not reported infected individuals in the surrounding areas, the wide circulation of virus through indirect contact (i.e. fomites or air ventilation systems) and; the high variability in some categories, as for example, in direct contact-patients suspected positive, where SARSCoV-2 RNA prevalences ranged between 0 and $25.8 \%$. This last category accounted for a lack of information in the primary research papers that were included in our study. Another reason for lack of significant results could be due to disinfection procedures that keep the level of surface contamination below certain levels, reducing our ability to highlight differences. As a matter of fact, the only pairwise difference observed in the univariate model was lost in the multivariate model.

The moderator "location of surface" was aimed at identifying a risk of surface contamination due to proximity to the virus source. The starting point was that surfaces in the same room as a spreading patient and surfaces in the same room and in close proximity to a patient, could be contaminated with higher frequency since virus-laiden respiratory droplets tend to settle and contaminate surfaces within a $1.8 \mathrm{~m}$ distance from the virus source [73]. The failure to confirm proximity to a virus source was associated with SARSCoV-2 RNA surface contamination could also be due to the disinfection procedures that keep the level of contamination below certain levels, deterring our analysis from highlighting differences. For this moderator too, some pairwise differences observed in the univariate model were lost in the multivariate one.
The moderator "duration of exposure" was significant in both univariate and multivariate models, suggesting that reduced duration of exposure of a surface to a virus source is the main factor explaining the variability of prevalence rates on surfaces and in healthcare settings. A reduced duration of exposure could be due to the presence of the virus source for a short time only or to frequently applied disinfection procedures, as occurs in healthcare settings.

If virus RNA is detectable around patients, on surfaces, and in the surrounding air, this likely relates only poorly to the possibility of transmitting the disease, since the presence of virus RNA does not hold or imply any information on virus viability. Among the retrieved studies, only six assessed SARS-CoV-2 viability and only three detected viable virus [30, 36, 59]. It is important to stress that in those studies that detected viable SARS-CoV-2, the analysed surfaces were all classified as high-risk. Only one study analyzing high-risk surfaces did not detect viable SARS-CoV-2 on any surfaces [69]. Studies analyzing low- and medium-risk surfaces did not report any viable SARS-CoV-2, despite the fact that some surfaces were RT-PCR positive [38, 66, 69].

Given the low number of studies testing virus viability, we cannot correlate the RNA prevalence with the possibility of fomite transmission. However, the potential for a virus to survive and to be transmitted via fomites also depends on virus type and characteristics. For example, the presence of viral envelope, as in SARS-CoV-2, is associated with relatively low virus resistance on surfaces [10]. Although prolonged survival of SARS-CoV-2 on surfaces has been proven (until 28 days), evidence of transmission from contaminated dry surfaces in real settings is still lacking, and direct person-to-person transmission remains the main route [11].

If droplets are inhaled, the minimal infectious dose must be reached [74]. To date, a minimal infectious dose has not been defined for SARS-CoV-2, although it is suspected to be as low as 50 particles [75].

Finally, we should also consider the efficiency of transmission. Data for bacteriophages showed the transmission efficiency ranges from $<0.01 \%$ to $80 \%$ for fomite to hand 
transmission, with smooth surfaces showing the highest efficiency, and around $33.90 \%$ for hand to lip transmission [76]. No data on the efficiency of transmission for SARS$\mathrm{CoV}-2$ are available at the present date.

\section{Limitations}

The present work has some limitations. Data used to estimate prevalences were based on RNA presence and neither quantitative information about genomic copies nor information about the presence of viable virus particles were available. Few papers assessed the viability of virus in positive samples, and only two tested all the samples with cell culture. Thus, the reported prevalence rates have a risk of overestimation as, in some cases, the virus RNA detected could be non-infective. Studies assessing virus viability failed in most cases to demonstrate it. However, previous investigations suggested that virus culturability is possible only with virus loads greater than $10-100$ $\mathrm{TCID}_{50} / \mathrm{ml}$ [77-79].

Another limitation is linked to the choice of samples within each study. Sampled surfaces were in most cases chosen based on risk of contact (i.e. on the risk the surfaces could be contaminated or could be able to transfer contamination). This is another characteristic of the included studies that could have led to an overestimation of real prevalence. To account for this, we categorized surfaces according to variables that were likely to increase the risk the surfaces could be contaminated. However, our categorization has some limitations due to the difficulty, in some cases, of us categorizing the studies without introducing a risk of subjectivity.

Each category has specific limitations. We used virus source to take into account patient status, but were unable to account for disease stage and amount of virus shed by patients. This is partly because not all studies reported these data and partly because in some cases it was not possible to directly pair the virus source with the surface. The location of surface was classified according to the descriptions in the included studies, but, especially for objects in the same room, a risk of misclassification exists. Moreover, any analysis of duration of exposure suffers from potential poor reporting of cleaning and disinfection procedures.

\section{Conclusions}

The risk a surface will be contaminated with SARS-CoV-2 RNA depends mainly on the duration of exposure to a virus source. Irrespective of the amount of viable virus, potential measures to reduce contamination need to include timely and appropriate cleaning and disinfection protocols for atrisk surfaces. The risk of surface contamination is of particular importance in healthcare settings. According to our scoring system, the risk can be considered very low where exposure to a virus source is limited in duration, as in most public areas, and high in areas where there is prolonged exposure to infected patients. Data for coronaviruses other than SARS-CoV-2 show that RNA from these viruses can sometimes be found in public areas, but no data specific for SARS-CoV-2 were retrieved. These results suggest adoption of a cautious approach as regards the widespread use of disinfectants in low-risk areas. This is due to the potential contribution of disinfectants to the increase of antimicrobial resistance [80,81], which is a global challenge for human and animal health.

\section{Appendix}

See Table 6. 


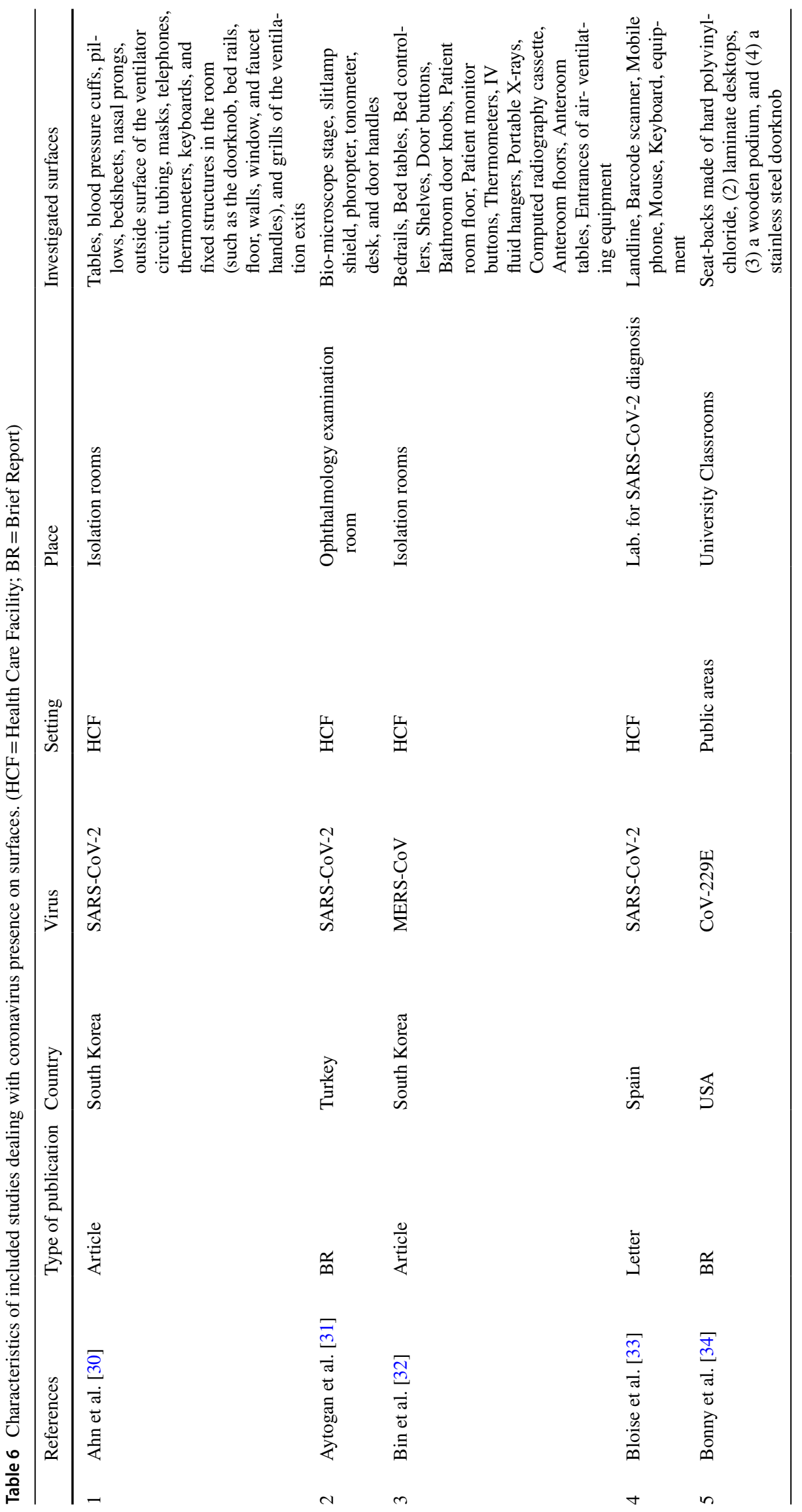




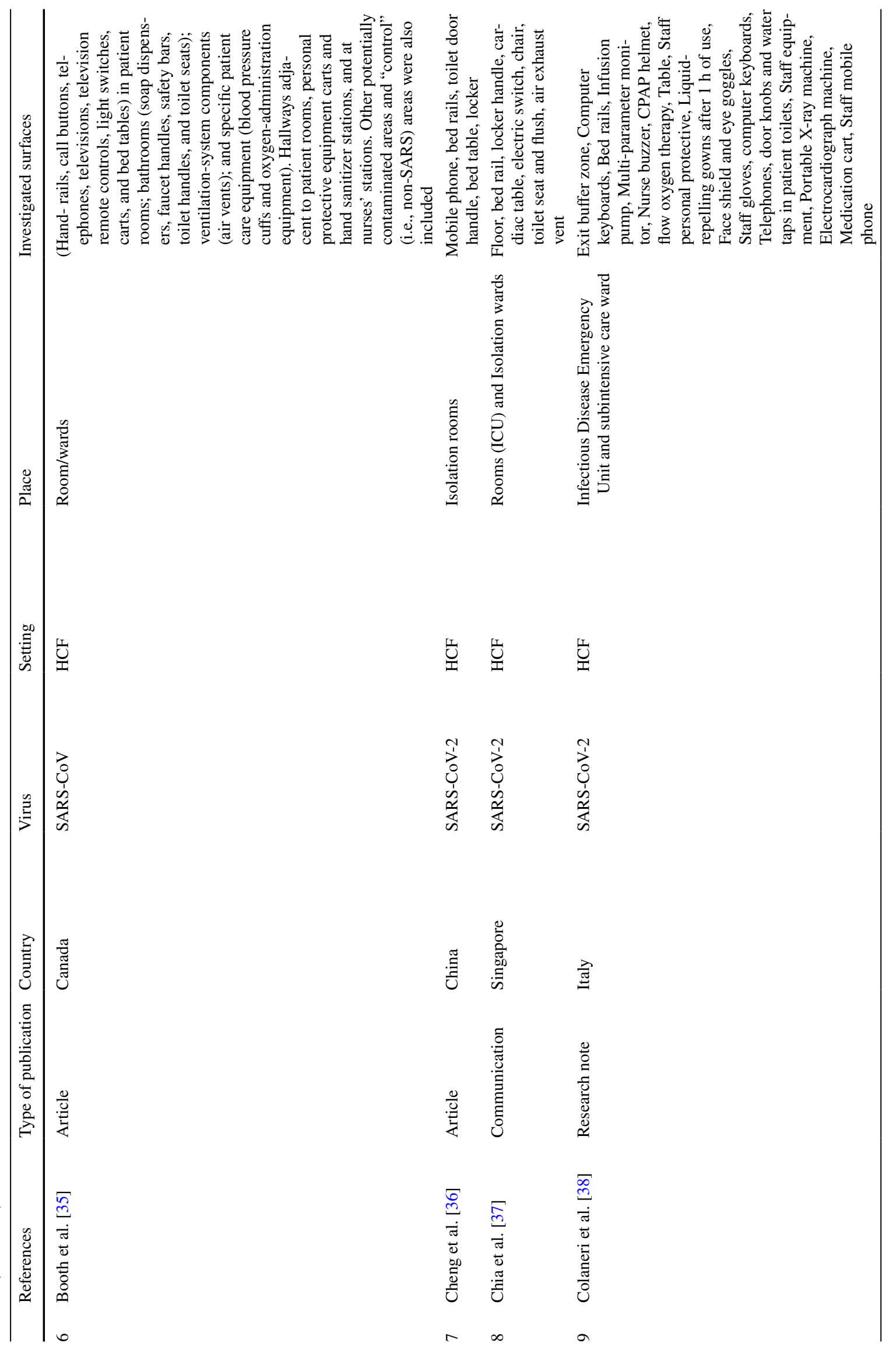




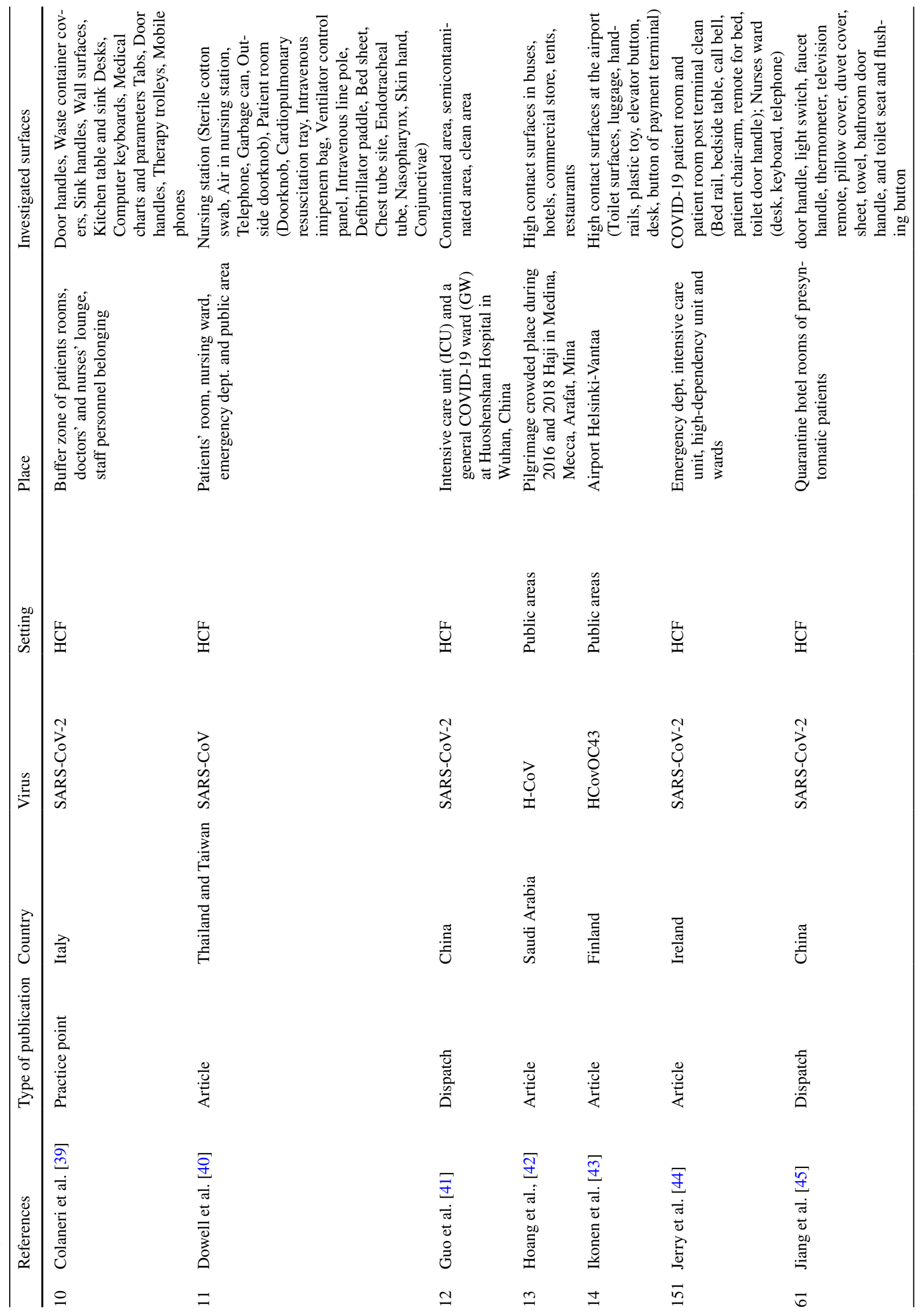




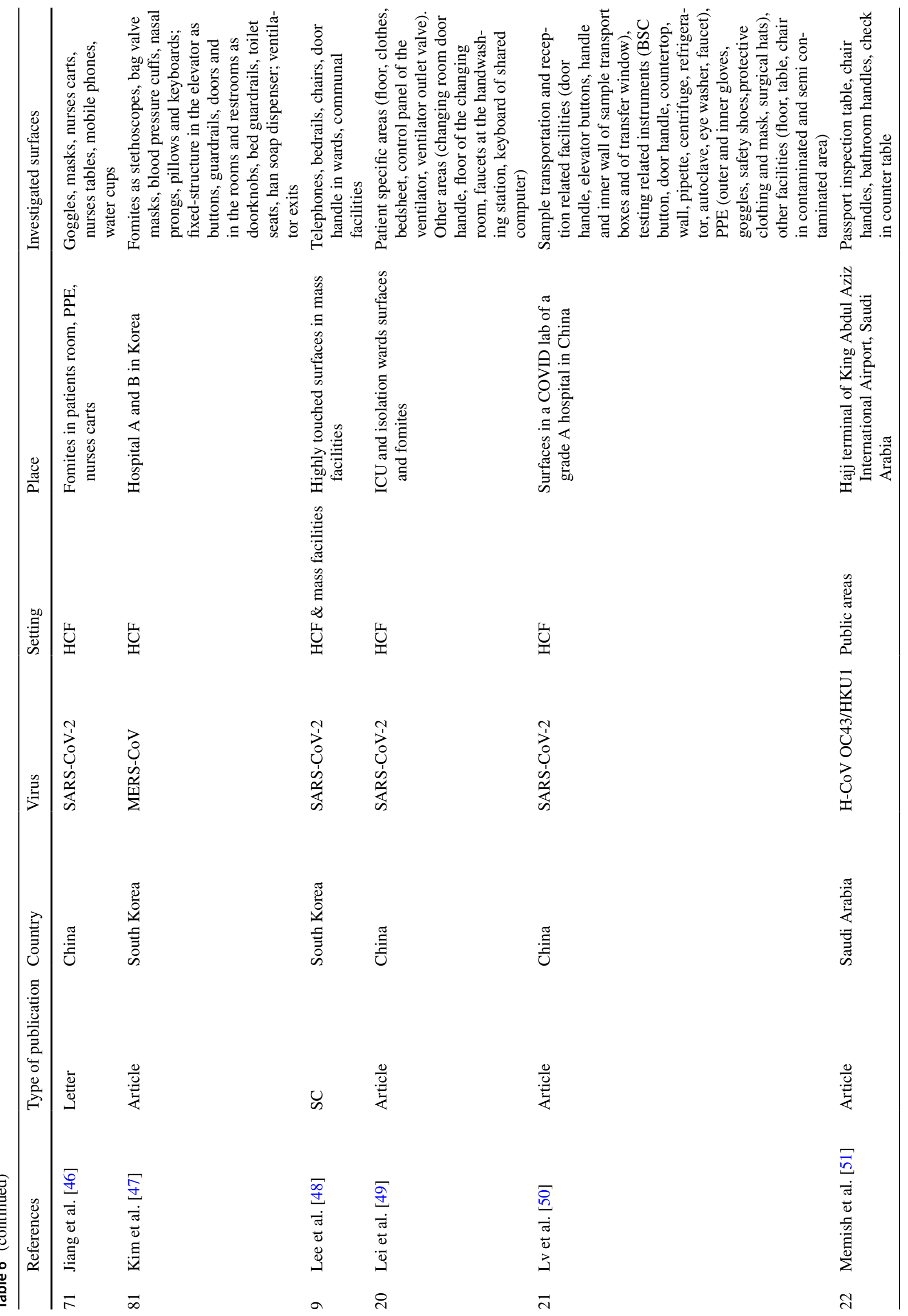




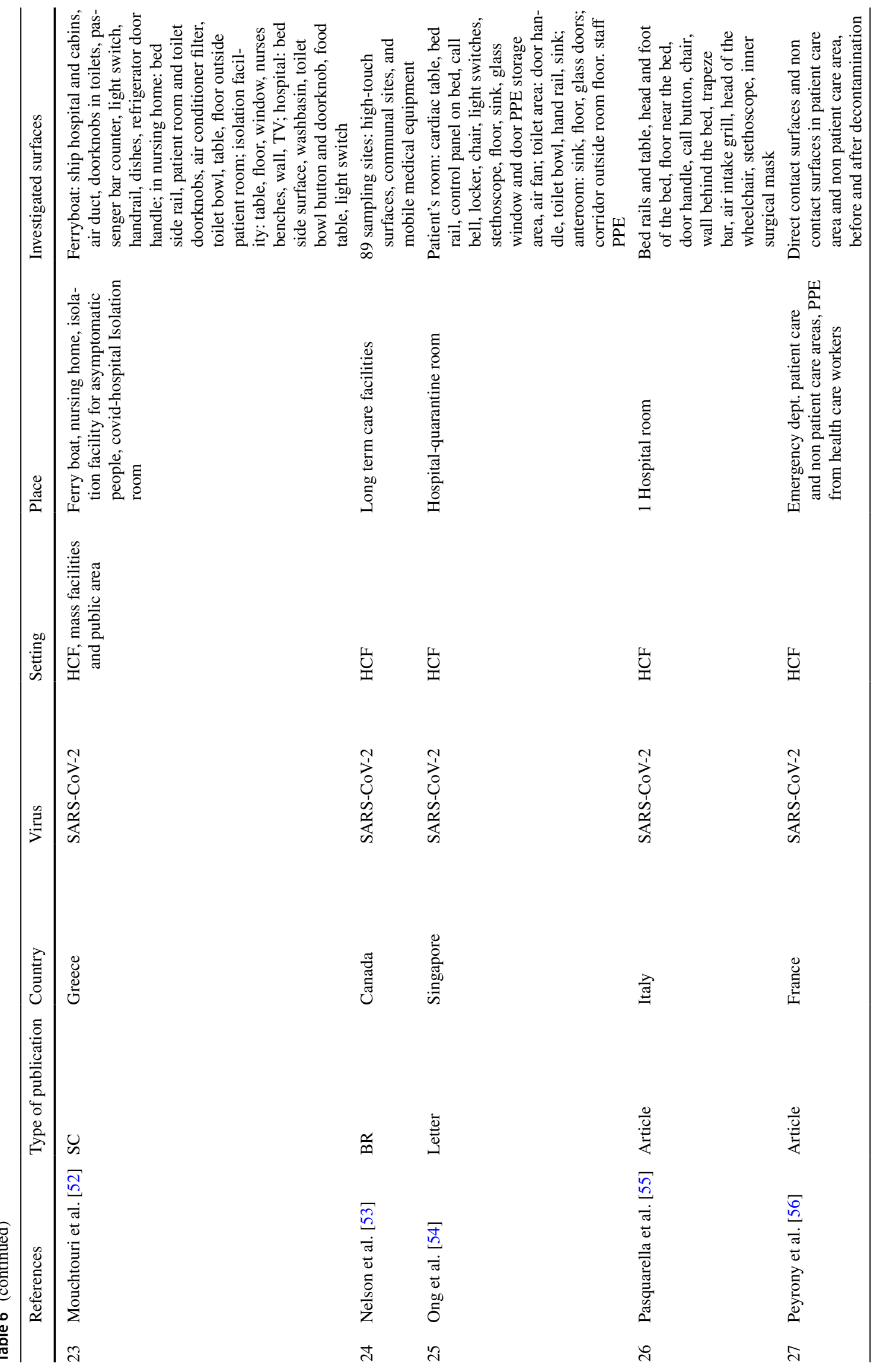




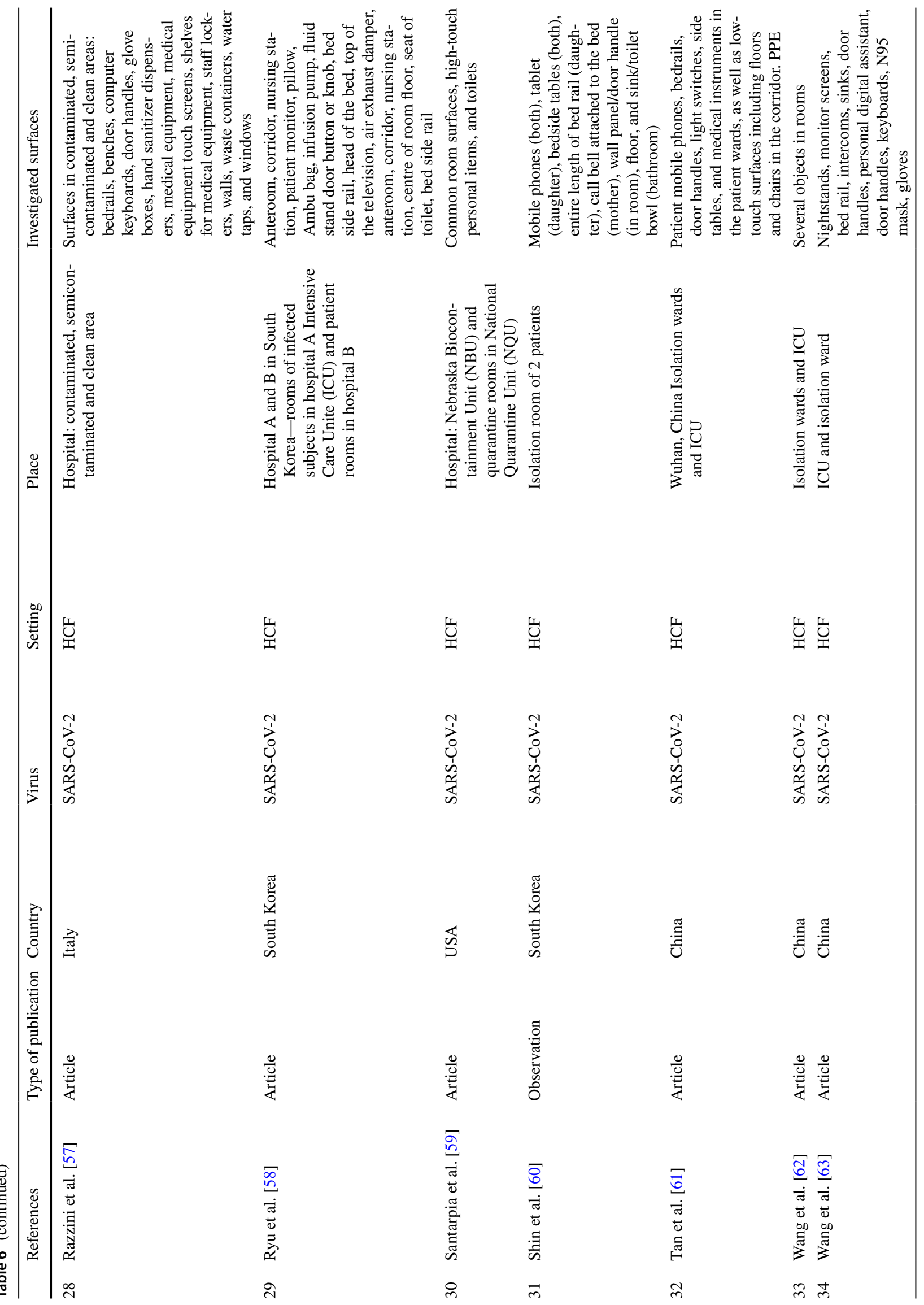




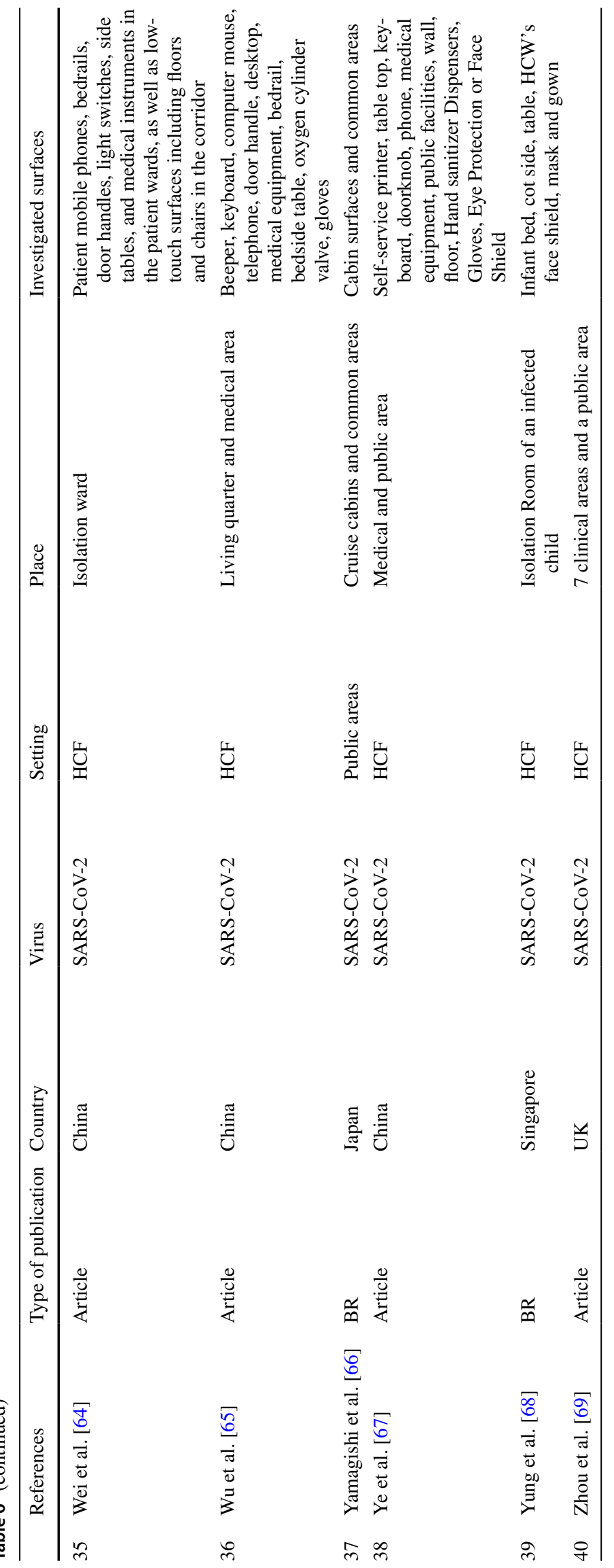


Supplementary Information The online version contains supplementary material available at https://doi.org/10.1007/s10654-021-00784-y.

\section{Declarations}

Conflict of interest The authors have no competing interests to declare.

\section{References}

1. John Hopkins University. Coronavirus resource center [Internet]. 2020 [cited 2020 Jan 4]. Available from: https://coronavirus.jhu. edu/map.html

2. COVID-19 Data Repository by the Center for Systems Science and Engineering (CSSE) at Johns Hopkins University [Internet]. Available from: https://github.com/CSSEGISandData/COVID-19

3. Johns Hopkins University \& Medicine. Mortality Analysis. [Internet]. Available from: https://coronavirus.jhu.edu/data/mortality

4. Yuki K, Fujiogi M, Koutsogiannaki S. COVID-19 pathophysiology: a review. Clin Immunol. 2020;215:108427.

5. Patel KP, Vunnam SR, Patel PA, Krill KL, Korbitz PM, Gallagher JP, et al. Transmission of SARS-CoV-2: an update of current literature. Eur J Clin Microbiol Infect Dis. 2020;39:2005.

6. Cai J, Sun W, Huang J, Gamber M, Wu J, He G. Indirect virus transmission in cluster of COVID-19 cases, Wenzhou, China, 2020. Emerg Infect Dis. 2020;26:1343.

7. Boone SA, Gerba CP. Significance of fomites in the spread of respiratory and enteric viral disease. Appl Environ Microbiol. 2007;73:1687.

8. Cozad A, Jones RD. Disinfection and the prevention of infectious disease. Am J Infect Control. 2003;31:243-54.

9. Rawlinson S, Ciric L, Cloutman-Green E. COVID-19 pandemic - let's not forget surfaces. J Hosp Infect. 2020. https://doi.org/10. 1016/j.jhin.2020.05.022.

10. Howie R, Alfa MJ, Coombs K. Survival of enveloped and nonenveloped viruses on surfaces compared with other micro-organisms and impact of suboptimal disinfectant exposure. J Hosp Infect. 2008;69:368-76.

11. Marzoli F, Bortolami A, Pezzuto A, Mazzetto E, Piro R, Terregino $\mathrm{C}$, et al. A systematic review of human coronaviruses survival on environmental surfaces. Sci Total Environ. 2021;778:146191.

12. FAO, WHO. COVID-19 and Food Safety: Guidance for food businesses: Interim guidance. COVID-19 Food Saf Guid food businesses Interim Guid. 2020;1-6.

13. Mahmood A, Eqan M, Pervez S, Alghamdi HA, Tabinda AB, Yasar A, et al. COVID-19 and frequent use of hand sanitizers; human health and environmental hazards by exposure pathways. Sci Total Environ. 2020. https://doi.org/10.1016/j.scitotenv.2020. 140561.

14. Thomas J, Brunton J, Graziosi S (2010) EPPI-Reviewer 4: software for research synthesis. London: Social science research unit, Institute of education: EPPI-Centre Software.

15. WHO Global. Surface sampling of coronavirus disease (COVID19): A practical "how to" protocol for health care and public health professionals. COVID-19 WHO Surveilllance, case Investig Epidemiol Protoc. 2020;1-26.

16. WHO. Surface sampling of coronavirus disease (COVID-19): A practical "how to" protocol for health care and public health professionals. 2020.

17. Viechtbauer W. Conducting meta-analyses in $\mathrm{R}$ with the metafor Package. J Stat Softw. 2010;36:1-48.

18. R Core Team. R: a language and environment for statistical computing. Vienna R Found. Stat. Comput. 2019.
19. Freeman MF, Tukey JW. Transformations related to the angular and the square root on JSTOR. Ann Math Stat. 1950;21:607-11.

20. Barendregt JJ, Doi S, Lee YY, Norman RE, Vos T. Meta-analysis of prevalence. J Epidemiol Commun Health. 2013;67:974-8.

21. Miller JJ. The inverse of the freeman-tukey double arcsine transformation. Am Stat. 1978;32:138.

22. Nakagawa S, Santos ESA. Methodological issues and advances in biological meta-analysis. Evol Ecol. 2012;26:1253-74.

23. Higgins JPT, Thompson SG. Quantifying heterogeneity in a metaanalysis. Stat Med. 2002;21:1539-58.

24. Viechtbauer W. Bias and efficiency of meta-analytic variance estimators in the random-effects model. J Educ Behav Stat. 2005;30:261-93.

25. Raudenbush SW. 16. Analyzing effect sizes: random-effects models. In: Cooper H, Hedges LV, Valentine JC, editors. Handb Res Synth meta-analysis. New York: Russel Sage Foundation; 2009.

26. Berkey CS, Hoaglin DC, Mosteller F, Colditz GA. Meta-analysis of multiple outcomes by regression with random effects. Stat Med. 1998;17:2537-50.

27. Benjamini Y, Hochberg Y. Controlling the false discovery rate: a practical and powerful approach to multiple testing on JSTOR. J R Stat Soc Ser B. 1995;57:289-300.

28. Hothorn T, Bretz F, Westfall P. Simultaneous inference in general parametric models. Biometrical J. 2008;50:346-63.

29. Stanley TD, Doucouliagos H. Meta-regression approximations to reduce publication selection bias. Res Synth Methods. 2014;5:60-78.

30. Ahn JY, An S, Sohn Y, Cho Y, Hyun JH, Baek YJ, et al. Environmental contamination in the isolation rooms of COVID-19 patients with severe pneumonia requiring mechanical ventilation or high-flow oxygen therapy. J Hosp Infect. 2020;106:570-6.

31. Aytogan H, Ayintap E, N OY. . Detection of coronavirus disease 2019 viral material on environmental surfaces of an ophthalmology examination room. JAMA Ophthalmol. 2020;138:990.

32. Bin SY, Heo JY, Song MS, Lee J, Kim EH, Park SJ, et al. Environmental contamination and viral shedding in MERS patients during MERS-CoV outbreak in South Korea. Clin Infect Dis. 2015;62:755-60.

33. Bloise I, Gómez-Arroyo B, García-Rodríguez J. Detection of SARS-CoV-2 on high-touch surfaces in a clinical microbiology laboratory. J Hosp Infect. 2020;105:784.

34. Bonny TS, Yezli S, Lednicky JA. Isolation and identification of human coronavirus 229E from frequently touched environmental surfaces of a university classroom that is cleaned daily. Am J Infect Control. 2018. https://doi.org/10.1016/j.ajic.2017. 07.014.

35. Booth TF, Kournikakis B, Bastien N, Ho J, Kobasa D, Stadnyk L, et al. Detection of Airborne Severe Acute Respiratory Syndrome (SARS) coronavirus and environmental contamination in SARS outbreak units. J Infect Dis. 2005;191:1472-7.

36. Cheng VC-C, Wong S-C, Chan VW-M, So SY-C, Chen JH-K, Yip $\mathrm{CC}-\mathrm{Y}$, et al. Air and environmental sampling for SARS-CoV-2 around hospitalized patients with coronavirus disease 2019 (COVID-19). Infect Control Hosp Epidemiol. 2020;106:570.

37. Chia PY, Coleman KK, Tan YK, Ong SWX, Gum M, Lau SK, et al. Detection of air and surface contamination by SARSCoV-2 in hospital rooms of infected patients. Nat Commun. 2020;11:2800.

38. Colaneri M, Seminari E, Novati S, Asperges E, Biscarini S, Piralla A, et al. Severe acute respiratory syndrome coronavirus 2 RNA contamination of inanimate surfaces and virus viability in a health care emergency unit. Clin Microbiol Infect England. 2020;26:1094.e1-1094.e5.

39. Colaneri M, Seminari E, Piralla A, Zuccaro V, Di Filippo A, Baldanti F, et al. Lack of SARS-CoV-2 RNA environmental contamination in a tertiary referral hospital for infectious diseases in 
Northern Italy. J Hosp Infect. 2020. https://doi.org/10.1016/j.jhin. 2020.03.018.

40. Dowell SF, Simmerman JM, Erdman DD, Wu JSJ, Chaovavanich A, Javadi M, et al. Severe acute respiratory syndrome coronavirus on hospital surfaces. Clin Infect Dis. 2004;39:652-7.

41. Guo Z-D, Wang Z-Y, Zhang S-F, Li X, Li L, Li C, et al. Aerosol and surface distribution of severe acute respiratory syndrome coronavirus 2 in hospital wards, Wuhan, China, 2020. Emerg Infect Dis. 2020;26:1583.

42. Hoang VT, Sow D, Belhouchat K, Dao TL, Ly TDA, Fenollar F, et al. Environmental investigation of respiratory pathogens during the Hajj 2016 and 2018. Travel Med Infect Dis. 2020;33:101500.

43. Ikonen N, Savolainen-Kopra C, Je E, Kulmala I, Pasanen P, Salmela A, et al. Deposition of respiratory virus pathogens on frequently touched surfaces at airports. BMC Infect Dis. 2018;18:437.

44. Jerry J, O'Regan E, O'Sullivan L, Lynch M, Brady D. Do established infection prevention and control measures prevent spread of SARS-CoV-2 to the hospital environment beyond the patient room? J Hosp Infect England. 2020;105:589-92.

45. Jiang F-C, Jiang X-L, Wang Z-G, Meng Z-H, Shao S-F, Anderson $\mathrm{BD}$, et al. Detection of severe acute respiratory syndrome coronavirus 2 RNA on surfaces in quarantine rooms. Emerg Infect Dis. 2020;26

46. Jiang Q, Chen Y, Dai Y, Cai S, Hu G. The presence and distribution of novel coronavirus in a medical environment. J Am Acad Dermatol. 2020;83:1218.

47. Kim SH, Chang SY, Sung M, Park JH, Bin Kim H, Lee H, et al. Extensive Viable Middle East Respiratory Syndrome (MERS) Coronavirus contamination in air and surrounding environment in MERS isolation wards. Clin Infect Dis. 2016;63:363-9.

48. Lee S, Dy L, Wg L, Kang B, Ys J, Ryu B, et al. Detection of novel coronavirus on the surface of environmental materials contaminated by COVID-19 patients in the Republic of Korea. Osong public Heal Res Perspect. 2020;11:128-32.

49. Lei H, Ye F, Liu X, Huang Z, Ling S, Jiang Z, et al. SARS-CoV-2 environmental contamination associated with persistently infected COVID-19 patients. Influenza Other Respi Viruses. 2020. https:// doi.org/10.1111/irv.12783.

50. Lv J, Yang J, Xue J, Zhu P, Liu L, Li S. Detection of SARS-CoV-2 RNA residue on object surfaces in nucleic acid testing laboratory using droplet digital PCR. Sci Total Environ. 2020;742:140370.

51. Memish ZA, Almasri M, Assirri A, Al-Shangiti AM, Gray GC, Lednicky JA, et al. Environmental sampling for respiratory pathogens in Jeddah airport during the 2013 Hajj season. Am J Infect Control. 2014. https://doi.org/10.1016/j.ajic.2014.07.027.

52. Mouchtouri V, Koureas M, Kyritsi M, Vontas A, Kourentis L, Sapounas S, et al. Environmental contamination of SARS-CoV-2 on surfaces, air-conditioner and ventilation systems. Int J Hyg Environ Health. 2020;230:113599.

53. Nelson A, Kassimatis J, Estoque J, Yang C, McKee G, Bryce E, et al. Environmental detection of severe acute respiratory syndrome coronavirus 2 (SARS-CoV-2) from medical equipment in long-term care facilities undergoing COVID-19 outbreaks. Am J Infect Control. 2020;49(2):265-8.

54. Ong SWX, Tan YK, Chia PY, Lee TH, Ng OT, Wong MSY, et al. Air, surface environmental, and personal protective equipment contamination by severe acute respiratory syndrome coronavirus 2 (SARS-CoV-2) from a symptomatic patient. JAMA - J Am Med Assoc. 2020;323:1610-2.

55. Pasquarella C, Me C, Bizzarro A, Veronesi L, Affanni P, Meschi T, et al. Detection of SARS-CoV-2 on hospital surfaces. Acta Biomed. 2020;91:76-8.

56. Peyrony O, Ellouze S, Salmona M, Feghoul L, et al. Surfaces and equipment contamination by severe acute respiratory syndrome coronavirus 2 (SARS-CoV-2) in the emergency department at a university hospital. Int J Hyg Environ Health. 2020;230:113600.

57. Razzini K, Castrica M, Menchetti L, Maggi L, Negroni L, NV O, , et al. SARS-CoV-2 RNA detection in the air and on surfaces in the COVID-19 ward of a hospital in Milan. Italy Sci Total Environ. 2020;742:140540.

58. Ryu B-H, Cho Y, Cho O-H, Hong SI, Kim S, Lee S. Environmental contamination of SARS-CoV-2 during the COVID-19 outbreak in South Korea. Am J Infect Control. 2020. https://doi.org/10. 1016/j.ajic.2020.05.027.

59. Santarpia JL, Rivera DN, Herrera VL, Morwitzer MJ, Creager H, Santarpia GW, et al. Aerosol and surface transmission potential of SARS-CoV-2. Sci Rep. 2020;10:1-19.

60. Shin K, Hs P, Lee J, Jk L. Environmental surface testing for severe acute respiratory syndrome coronavirus 2 (SARS-CoV-2) during prolonged isolation of an asymptomatic carrier. Infect Control Hosp Epidemiol. 2020;11:1328.

61. Tan L, Ma B, Lai X, Han L, Cao P, Zhang J, et al. Air and surface contamination by SARS-CoV-2 virus in a tertiary hospital in Wuhan. China Int J Infect Dis Canada. 2020;99:3-7.

62. Wang Y, Qiao F, Zhou F, Yuan Y. Surface distribution of severe acute respiratory syndrome coronavirus 2 in Leishenshan Hospital in China. Indoor Built Environ. 2020;0:1-9.

63. Wang J, Feng H, Zhang S, Ni Z, Ni L, Chen Y, et al. SARS-CoV-2 RNA detection of hospital isolation wards hygiene monitoring during the Coronavirus Disease 2019 outbreak in a Chinese hospital. Int J Infect Dis. 2020. https://doi.org/10.1016/j.ijid.2020.04. 024.

64. Wei L, Lin J, Duan X, Huang W, Lu X, Zhou J, et al. Asymptomatic COVID-19 Patients can contaminate their surroundings: an environment sampling study. Appl Env Sci. 2020;5:e00442-20.

65. Wu S, Wang Y, Jin X, Tian J, Liu J, Mao Y. Environmental contamination by SARS-CoV-2 in a designated hospital for coronavirus disease 2019. Am J Infect Control. 2020. https://doi.org/10. 1016/j.ajic.2020.05.003.

66. Yamagishi T, Ohnishi M, Matsunaga N, Kakimoto K, Kamiya $\mathrm{H}$, Okamoto K, et al. Environmental sampling for severe acute respiratory syndrome coronavirus 2 during COVID-19 outbreak in the Diamond Princess cruise ship. J Infect Dis. 2020;222:1098.

67. Ye G, Lin H, Chen S, Wang S, Zeng Z, Wang W, et al. Environmental contamination of SARS-CoV-2 in healthcare premises. J Infect. 2020;81:e1-5.

68. Yung CF, Kam K, Wong MSY, Maiwald M, Tan YK, Tan BH, et al. Environment and personal protective equipment tests for SARS-CoV-2 in the isolation room of an infant with infection. Ann Intern Med. 2020. https://doi.org/10.7326/M20-0942.

69. Zhou J, Otter JA, Price JR, Cimpeanu C, Garcia DM, Kinross J, et al. Investigating SARS-CoV-2 surface and air contamination in an acute healthcare setting during the peak of the COVID-19 pandemic in London. Clin Infect Dis. 2020. https://doi.org/10. 1093/cid/ciaa905/5868534.

70. Ikonen N, Savolainen-Kopra C, Enstone JE, Kulmala I, Pasanen $\mathrm{P}$, Salmela A, et al. Deposition of respiratory virus pathogens on frequently touched surfaces at airports. BMC Infect Dis BMC Infectious Diseases. 2018;18:1-7.

71. Dowell SF, Simmerman JM, Erdman DD, Wu J-SJ, Chaovavanich A, Javadi M, et al. Severe acute respiratory syndrome coronavirus on hospital surfaces. Clin Infect Dis. 2004;39:652-7.

72. McDaniel MA, Whetzel DL, Schmidt FL, Maurer SD. The validity of employment interviews: a comprehensive review and metaanalysis. J Appl Psychol. 1994;79:599-616.

73. Mittal R, Ni R, Seo JH. The flow physics of COVID-19. J Fluid Mech. 2020;894:1-14.

74. de Gabory L, Alharbi A, Kérimian M, Lafon ME. The influenza virus, SARS-CoV-2, and the airways: Clarification for the 
otorhinolaryngologist. Eur Ann Otorhinolaryngol Head Neck Dis. 2020. https://doi.org/10.1016/j.anorl.2020.05.015.

75. Kolinski JM, Schneider TM. Superspreading events suggest aerosol transmission of SARS-CoV-2 by accumulation in enclosed spaces. Phys Rev. 2021;E103:033109.

76. Rusin P, Maxwell S, Gerba C. Comparative surface-to-hand and fingertip-to-mouth transfer efficiency of gram-positive bacteria, gram-negative bacteria, and phage. J Appl Microbiol. 2002;93:585-92.

77. Chin AWH, Chu JTS, Perera MRA, Hui KPY, Yen H-L, Chan $\mathrm{MCW}$, et al. Stability of SARS-CoV-2 in different environmental conditions. The Lancet Microbe. Elsevier; 2020;1:e10.

78. Kratzel A, Steiner S, Todt D, Brueggemann Y, Steinmann J, Steinmann E, et al. Temperature-dependent surface stability of SARSCoV-2. J Infect. 2020;81:452-82.

79. Rabenau HF, Cinatl J, Morgenstern B, Bauer G, Preiser W, Doerr HW. Stability and inactivation of SARS coronavirus. Med Microbiol Immunol. 2005;194:1-6.
80. Conficoni D, Losasso C, Cortini E, Di Cesare A, Cibin V, Giaccone $\mathrm{V}$, et al. Resistance to biocides in Listeria monocytogenes collected in meat-processing environments. Front Microbiol. 2016;7:1-9.

81. Marzoli F, Turchi B, Pedonese F, Torracca B, Bertelloni F, Cilia $\mathrm{G}$, et al. Coagulase negative staphylococci from ovine bulk-tank milk: Effects of the exposure to sub-inhibitory concentrations of disinfectants for teat-dipping. Comp Immunol Microbiol Infect Dis. 2021;76:101656.

Publisher's Note Springer Nature remains neutral with regard to jurisdictional claims in published maps and institutional affiliations. 